\title{
molecules
}

ISSN 1420-3049

www.mdpi.com/journal/molecules

Article

\section{In Vitro Antioxidant Activities, Free Radical Scavenging Capacity, and Tyrosinase Inhibitory of Flavonoid Compounds and Ferulic Acid from Spiranthes sinensis (Pers.) Ames}

\author{
Chung Pin Liang ${ }^{2}$, Chia Hao Chang ${ }^{1}$, Chien Cheng Liang ${ }^{3}$, Kuei Yu Hung ${ }^{4}$ \\ and Chang Wei Hsieh ${ }^{1, *}$
}

1 Department of Medicinal Botanicals and Health Applications, Da-Yeh University, Changhua 51591, Taiwan; E-Mail: q8528852@hotmail.com

2 Cheng Ching General Hospital, Taichung 42881, Taiwan; E-Mail: hideben@hotmail.com

3 Horien International Co., Ltd., Taichung 42881, Taiwan; E-Mail: jasonliang@hydron.com.tw

4 Pemay Biomedical Technology Corp, Taichung 41348, Taiwan; E-Mail: pemay321@gmail.com

* Author to whom correspondence should be addressed; E-Mail: welson@mail.dyu.edu.tw;

Tel.: +886-4-8511-888 (ext. 1790); Fax: +886-4-8511-349.

Received: 24 January 2014; in revised form: 2 April 2014 / Accepted: 3 April 2014 /

Published: 15 April 2014

\begin{abstract}
In this study, ultrasound-assisted extraction (UAE) and other methods of extracting flavonoid compounds and ferulic acid (FA) from $S$. sinensis were investigated. Five different extraction methods, including water extraction (W), water extraction using UAE (W+U), 75\% ethanol extraction (E), 75\% ethanol extraction using UAE (E+U), and supercritical $\mathrm{CO}_{2}$ extraction ( $\mathrm{SFE}$ ) were applied in the extraction of bioactive compounds (flavonoids and ferulic acid) in order to compare their efficiency. The highest yield of flavonoids $(4.28 \mathrm{mg} / \mathrm{g})$ and ferulic acid $(4.13 \mathrm{mg} / \mathrm{g})$ content was detected in the $\mathrm{E}+\mathrm{U}$ extract. Furthermore, $S$. sinensis extracts obtained by E+U show high antioxidant activity, and $\mathrm{IC}_{50}$ values of $0.47 \mathrm{mg} / \mathrm{mL}$ for DPPH radicals and $0.205 \mathrm{mg} / \mathrm{mL}$ for metal chelating activity. The total antioxidant assay shows superoxide radical scavenging capacity and in vitro mushroom tyrosinase inhibition in a dose-dependent manner, suggesting that $\mathrm{E}+\mathrm{U}$ can be used for extraction of bioactive compounds from $S$. sinensis.
\end{abstract}

Keywords: Spiranthes sinensis; ultrasound-assisted extraction; ferulic acid; flavonoids; antioxidant activity; tyrosinase 


\section{Introduction}

Spiranthes sinensis (Pers.) Ames is a famous Traditional Chinese Medicine herb which is widely used in the treatment of bacterial and inflammatory diseases, cancer and blood and chest disorders [1,2]. Previous investigations of $S$. sinensis have yielded flavonoids, homocyclotriucallane, dihydrophenanthrenes and ferulic acid (FA) [3,4].

Flavonoids comprise the major class of phenolic compounds widely present in natural plant tissues [5]. They are highly effective antioxidants and less toxic than synthetic antioxidants [6]. Isolated flavonoid compounds from Trifolium nigrescens Subsp. Petrisavi have antioxidant and tyrosinase inhibitory activities [7]. FA is a hydroxycinnamic acid widely present in plants and vegetable foods. Its biological properties such as antioxidant activity and tyrosinase inhition are well recognized [8,9]. The special structure of FA also endows it with strong UV-absorptive ability, making it an important skin-protecting agent [10]. All this justifies the great attention paid to finding an effective method to extract flavonoids and FA from $S$. sinensis.

At present, commonly used extraction methods include: solvent extraction, Soxhlet extraction and microwave-assisted extraction. These methods have both advantages and disadvantages. For example, solvent extraction can result in polarity differences in the compounds, and the extracted substance may remain toxic; Soxhlet extractions can reduce the amount of solvent needed, but require a long extraction time; and microwave-assisted extraction provides very rapid and efficient extraction [11], but the equipment is expensive. In order to seek more environmentally friendly methods which would decrease solvent consumption, shorten extraction times, increase extraction yields and enhance the quality of extracts, ultrasound-assisted extraction (UAE) and supercritical carbon dioxide extraction (SFE) have been developed. Compared with other extraction techniques, UAE and SFE are efficient alternatives, and their operations are easier $[12,13]$. UAE has proved to be a particularly effective extraction method to reduce the extraction temperature and amount of solvent and shorten the extraction time, which is especially useful for the extraction of thermosensitive and unstable compounds. Therefore, UAE has been widely used in the literature for the extraction of biologically active compounds, including the extraction of polyphenols and flavonoids from yellow tea [14]. In recent years, many studies have been done to use SFE with carbon dioxide $\left(\mathrm{CO}_{2}\right)$ as a solvent for extraction of natural compounds from different raw materials [15]. The combined liquid-like solvating capabilities and gas-like transport properties of supercritical fluids make them particularly suitable for extracting bioactive compounds from plant tissues with a high degree of recovery in a short period of time. It was believed that, by using SFE, the extraction time can be reduced to tens of minutes compared with liquid-solid extraction that requires hours or days [16].

It has been reported that some extraction methods have been used for extracting bioactive compounds from S. sinensis. Zhao et al. [17] extracted flavonoid compounds from S. sinensis as follows: extraction time $3 \mathrm{~h}, 75 \%$ ethanol, and a solid-to-solvent ratio of 1:40. Those extractions are similar to ours, however, their extractions did not use UAE or controlled temperature and required a long extraction time. Dong et al. [18] and Peng et al. [2] used a large amount of S. sinensis powder: 10 and $5 \mathrm{~kg}$, respectively, for reflux extraction to extract flavonoids. 
Therefore, the aim of this study was to investigate the most efficient way of extracting flavonoid compounds and FA from $S$. sinensis and to evaluate the antioxidant activities and in vitro tyrosinase activity in the extracts obtained by $\mathrm{E}+\mathrm{U}$.

\section{Results and Discussion}

\subsection{Discussion of the Five Different Extraction Methods to Obtain a Higher Content of Flavonoids and Ferulic Acid}

Figure 1 shows our results for the five different extraction methods: water extraction (W), water extraction using UAE $(\mathrm{W}+\mathrm{U}), 75 \%$ ethanol extraction $(\mathrm{E}), 75 \%$ ethanol extraction using UAE (E+U) and supercritical $\mathrm{CO}_{2}$ extraction (SFE). The $\mathrm{W}$ extraction had a flavonoid content of $2.64 \mathrm{mg} / \mathrm{g}$ and FA content of $0.68 \mathrm{mg} / \mathrm{g}$; W+U extraction had a flavonoid content of $4.04 \mathrm{mg} / \mathrm{g}$ and FA content of $1.08 \mathrm{mg} / \mathrm{g}$; E extraction had a flavonoid content of $3.32 \mathrm{mg} / \mathrm{g}$ and FA content of $2.87 \mathrm{mg} / \mathrm{g}$; E+U extraction had a flavonoid content of $4.28 \mathrm{mg} / \mathrm{g}$ and FA content of $4.13 \mathrm{mg} / \mathrm{g}$; and SFE extraction had a flavonoid content of $4.12 \mathrm{mg} / \mathrm{g}$ and FA content of $2.50 \mathrm{mg} / \mathrm{g}$. The total yields of the extractions by $\mathrm{W}, \mathrm{W}+\mathrm{U}, \mathrm{E}, \mathrm{E}+\mathrm{U}$ and SFE extraction were thus $2.8 \%, 3.4 \%, 3.2 \%, 4 \%$ and $7.4 \%$, respectively. The flavonoid and FA yield ratio of different extraction methods were as follows: in solvent extraction methods, the flavonoid and FA yield ratio of the E extraction $(3.32 \mathrm{mg} / \mathrm{g}, 2.87 \mathrm{mg} / \mathrm{g})$ were higher than that of the $\mathrm{W}$ extraction $(2.64 \mathrm{mg} / \mathrm{g}, 0.68 \mathrm{mg} / \mathrm{g})$. In the ultrasound extraction methods, the flavonoid and FA yield ratios of $\mathrm{E}+\mathrm{U}$ extraction $(4.28 \mathrm{mg} / \mathrm{g}, 4.13 \mathrm{mg} / \mathrm{g})$ were higher than those of the $\mathrm{W}+\mathrm{U}$ extraction $(4.04 \mathrm{mg} / \mathrm{g}, 1.08 \mathrm{mg} / \mathrm{g})$. These results indicated that the E+U extraction was more efficient in extracting flavonoids and FA from $S$. sinensis.

In the Lina et al. study [19], the ethanol extraction resulted in higher phenolic compounds than the water extraction from coffee silverskin. A comparison of the ultrasound and non-ultrasound extraction of flavonoids from yellow tea showed that the flavonoid content produced by ultrasound-assisted extraction at $75 \%$ ethanol was higher than the others (water, 75\% ethanol, ultrasound-assisted extraction with water) [14]. This study proves that E+U extraction could successfully be used for extraction of flavonoids and FA from $S$. sinensis.

In our results, the SFE extraction of flavonoid compounds and FA from $S$. sinensis was less effective than that of ultrasonic extraction, possibly because the pressure (14 MPa) was not high enough. In Bruni et al.'s study [20], the use of ultrasonic extraction was compared with SFE for extracting vitamin E from Amaranthus caudatus seeds, and the results showed that the SFE extraction of vitamin E was superior to the UAE method. They used a pressure of $40 \mathrm{MPa}$, but the energy losses increased, with a resulting relative increase in the cost.

These studies have suggested that UAE is more efficient than conventional solvent extraction without UAE in extracting bioactive compounds from different natural sources. UAE was faster and more efficient in extracting bioactive components due to the strong disruption of sample tissue structure under ultrasonic acoustic cavitation. The E+U extraction was chosen for extracting the total flavonoid components and FA used for further antioxidant activities and in vitro tyrosinase activity. 
Figure 1. Comparison of the five extraction methods for obtaining flavonoids and FA. (1) W, water extraction; (2) $\mathrm{W}+\mathrm{U}$, water extraction using UAE; (3) E, 75\% ethanol extraction; (4) $\mathrm{E}+\mathrm{U}, 75 \%$ ethanol extraction using UAE; (5) SFE, supercritical $\mathrm{CO}_{2}$ extraction. a, b, c describe bioactive compound levels: a, the highest then the others; $\mathrm{c}$, the lowest then the others; $b$, middle of $a$ and $c$.

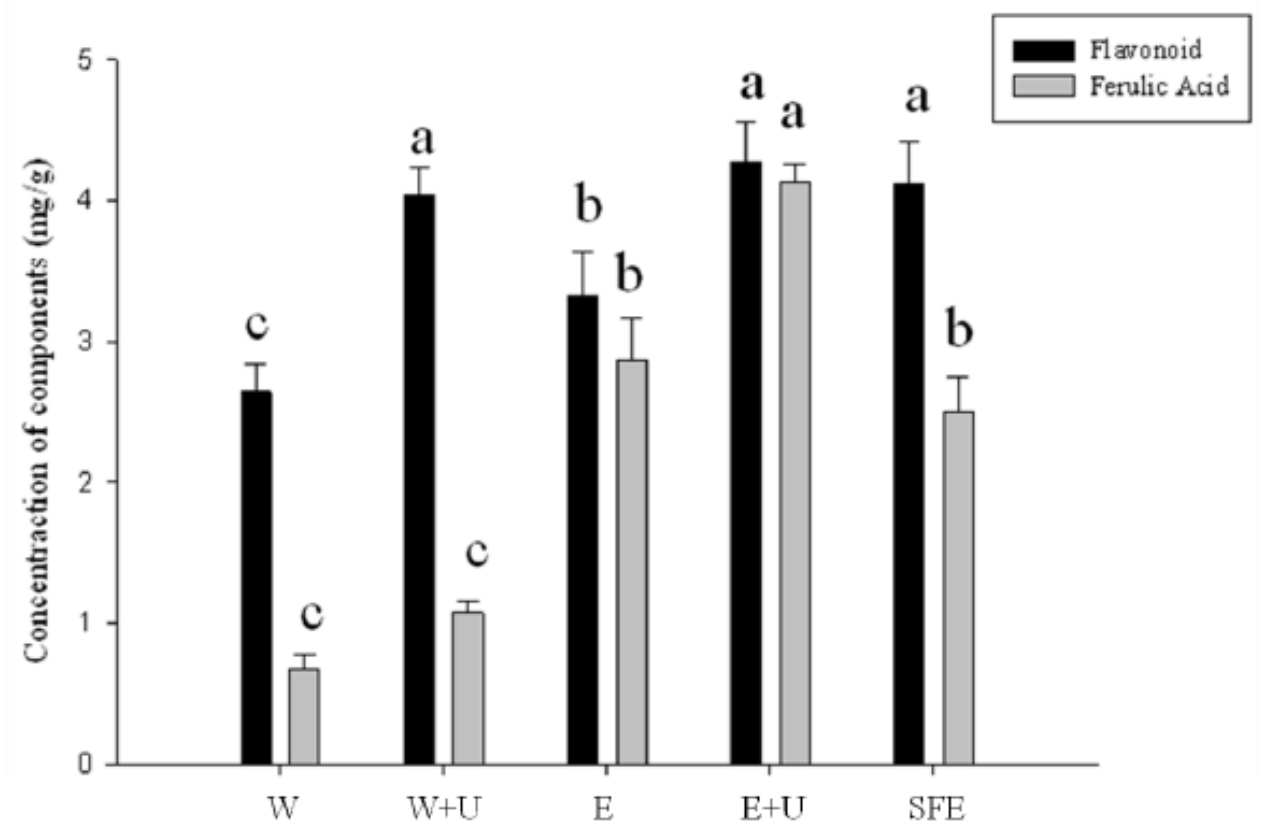

\subsection{DPPH Radical Scavenging Capacity}

After determining $\mathrm{E}+\mathrm{U}$ extraction to be the most efficient extraction process of $S$. sinensis, we investigated the antioxidant abilities of $S$. sinensis extract processed under specific extraction conditions, as the antioxidant bioactivities of plants might be a main contributor to their biological functions, including their hepetoprotective properties. The DPPH scavenging effects increased with increased concentrations of $S$. sinensis extract (Figure 2). The $\mathrm{IC}_{50}$ of DPPH radical scavenging activity of $S$. sinensis extract was $0.47 \mathrm{mg} / \mathrm{mL}$; it showed $92 \%$ DPPH radical scavenging ability at a concentration of $1.2 \mathrm{mg} / \mathrm{mL}$, similar to vitamin C. You et al.'s [21] results show that the ethanol extract and purified pigments from Castanea mollissima shells (CPS) possessed excellent DPPH scavenging capacity. Flavonoids have a diphenylpropane structure, in which the B or A ring of the structure contains catechol: C-3 includes either hydroxy or gallic acid (galloyl group), C-2 and C-3 are linked by a double bond and $\mathrm{C}-4$ is in a keto form. These provide flavonoids with their free radical scavenging capacity [22].

In the antioxidant system, oxidation is accompanied by reduction. An antioxidant index is the measurement of the reducing power [23]. The antioxidant capacity can be measured from absorbance values; the higher the absorbance, the greater the antioxidant capacity. As indicated in Figure 2, the higher the concentration of vitamin $\mathrm{C}$ and $\mathrm{S}$. sinensis $\mathrm{E}+\mathrm{U}$ extract, the greater the antioxidant property.

Although the data (Figure 2) showed that $S$. sinensis $\mathrm{E}+\mathrm{U}$ extract had a slightly lower free radical scavenging effect and reducing power than synthetic vitamin C, S. sinensis E+U extract is a natural product with an efficient scavenging power that should have a higher commercial value. 
Figure 2. DPPH radical scavenging capacity of $S$. sinensis $\mathrm{E}+\mathrm{U}$ extract. The DPPH scavenging effects of the extract at different concentrations compared with vitamin $\mathrm{C}$. Results are represented as percentages of control, and the data are mean $\pm \mathrm{SD}$ for the three separate experiments.

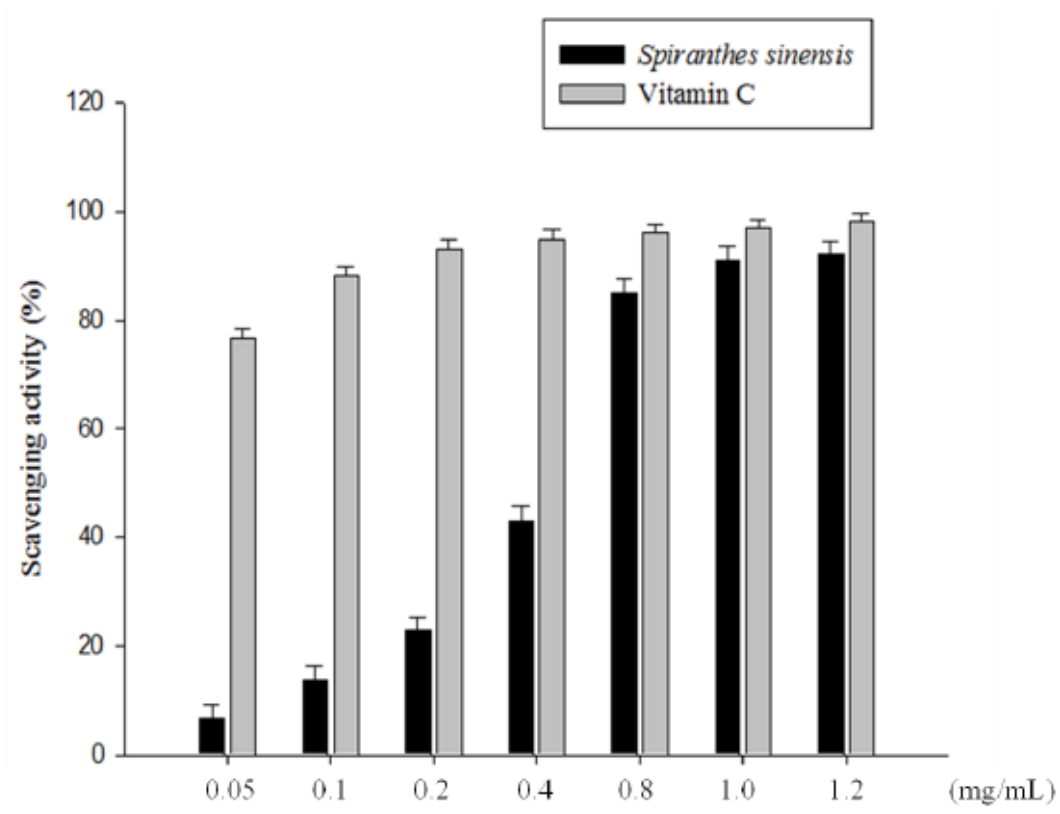

\subsection{Metal Chelating Activity}

Ferrozine can quantitatively form complexes with $\mathrm{Fe}^{2+}$. In the presence of other chelating agents or antioxidants, the complex formation is disrupted, with the result that the purple color of the complexes decreases. The effect of $S$. sinensis $\mathrm{E}+\mathrm{U}$ extract on the chelating ability of ferrous ion is shown in Figure 3. As can be seen, the $\mathrm{IC}_{50}$ of the metal-ion chelating capacity of $S$. sinensis $\mathrm{E}+\mathrm{U}$ extract $(0.05,0.1,0.2,0.4,0.8,1.0$ and $1.2 \mathrm{mg} / \mathrm{mL})$ was $0.205 \mathrm{mg} / \mathrm{mL}$, for a metal-ion chelating ability of $92 \%$ at a concentration of $1.2 \mathrm{mg} / \mathrm{mL}$. Furthermore, the metal chelating activity of the obtained extracts was slightly lower than that of EDTA at the same concentration. This result indicated that S. sinensis extract obtained by UAE had significant metal chelating activity; furthermore, the effect increased with increases in the concentration of $S$. sinensis extract.

\subsection{Total Antioxidant Activity}

Figure 4 shows the total antioxidant ability of $S$. sinensis $\mathrm{E}+\mathrm{U}$ extract as compared with Trolox as the control standard. It appeared that the total antioxidant ability of the obtained extracts was primarily related to their concentrations. The total antioxidant activity of the $S$. sinensis $\mathrm{E}+\mathrm{U}$ extract $(0.05,0.1,0.2,0.4,0.8$ and $1.0 \mathrm{mg} / \mathrm{mL})$ assay was compared with that of Trolox. At a concentration of $1.0 \mathrm{mg} / \mathrm{mL}$, the $S$. sinensis E+U extract total antioxidant ability was $42.0 \%$, and standard Trolox was 93\%. In the present study, the S. sinensis E+U extract thus showed lower free radical scavenging activities as compared to Trolox.

It has been reported that bioactive compounds extracted by solvent extraction and partitioned by ethyl acetate show good DPPH radical and ABTS scavenging capacity [24]. However, in previous 
studies, the extraction methods used to extract bioactive compounds from $S$. sinensis were complex. In our study, the E+U extraction was simple and required a short extraction time to extract bioactive compounds from $S$. sinensis.

Figure 3. Metal-ion chelating activity of $S$. sinensis $\mathrm{E}+\mathrm{U}$ extract. Various concentrations of the extract or EDTA were used in the study. Results are represented as percentages of control, and the data are mean $\pm \mathrm{SD}$ for the three separate experiments.

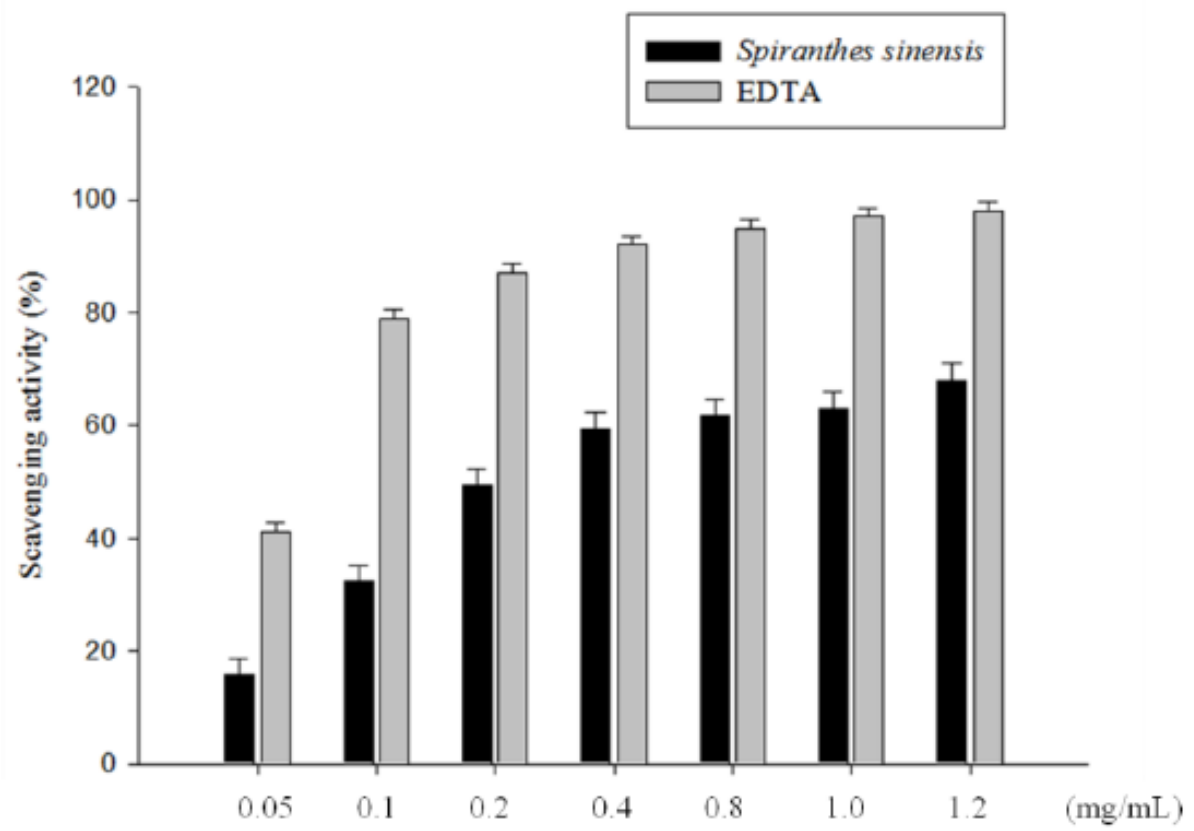

Figure 4. Total antioxidant activity of $S$. sinensis E+U extract. Different concentrations of the extract or Trolox were used in the study. Results are represented as percentages of control, and the data are mean $\pm \mathrm{SD}$ for the three separate experiments.

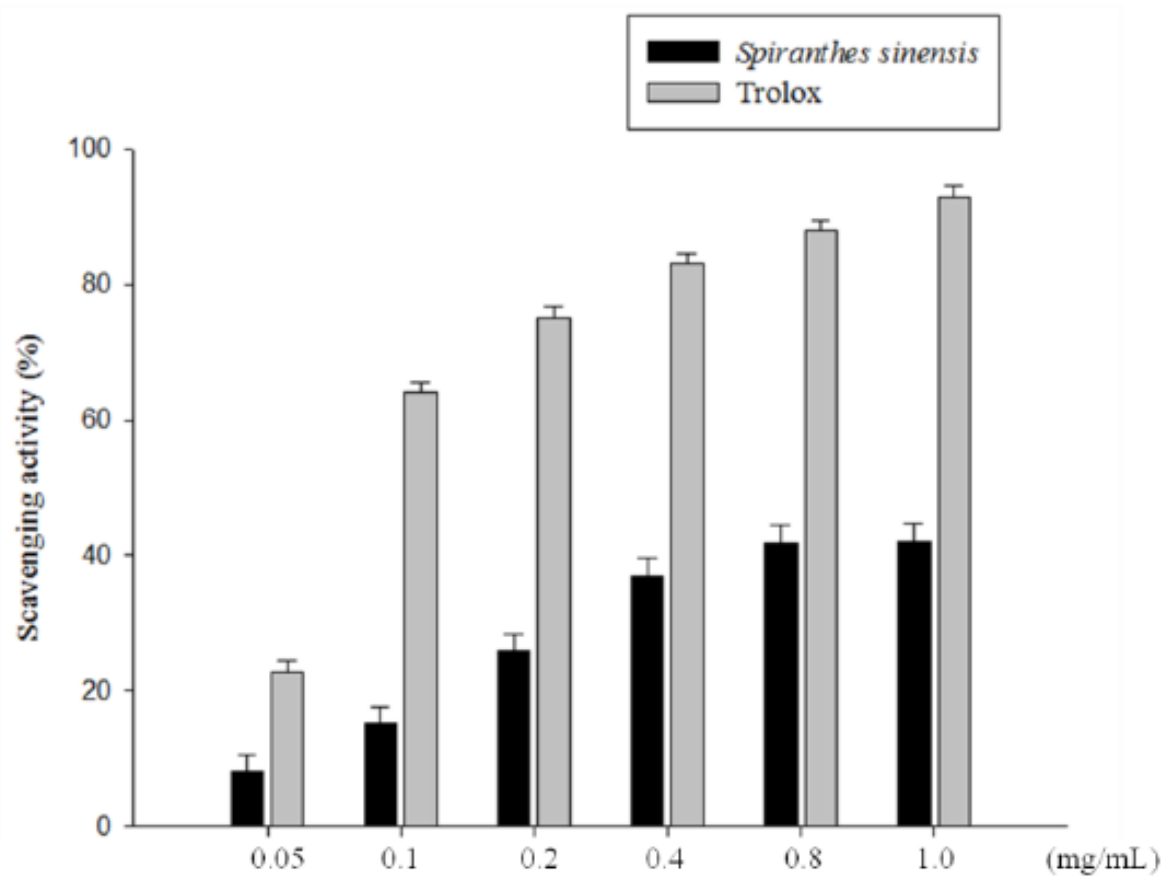




\subsection{Assay of Superoxide Radical Scavenging Capacity}

Superoxide anions are generated by the oxidation of pyrogallol, and the scavenging effects are expressed as the inhibition of pyrogallol autoxidation, so any substance existing in the reaction system that might affect the oxidation of pyrogallol might also affect the test results. The $S$. sinensis $\mathrm{E}+\mathrm{U}$ extract inhibited the hydroxylation of salicylic acid by reactive oxygen species in a dose-dependent manner. The reduction of total oxidation products as a function of the volume of the extract added to the assay is shown in Figure 5.

Figure 5. Superoxide radical scavenging capacity of $S$. sinensis E+U extract. The scavenging effects of the extract at different concentrations compared with vitamin $\mathrm{C}$. Results are represented as percentages of control, and the data are mean $\pm \mathrm{SD}$ for the three separate experiments.

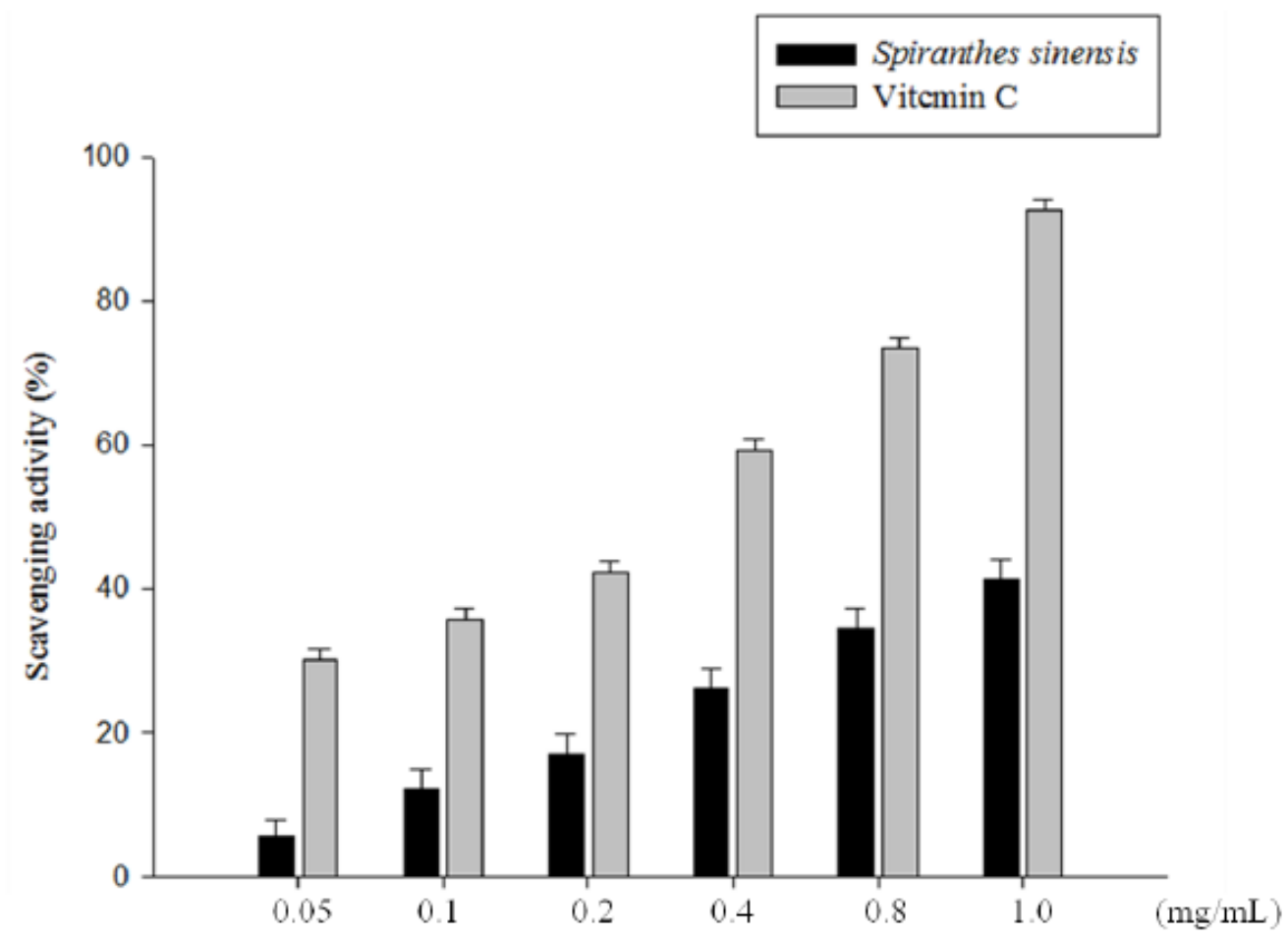

The superoxide radical scavenging activities of $S$. sinensis $\mathrm{E}+\mathrm{U}$ extract and Vitamin C $(0.05,0.1,0.2,0.4,0.8,1.0$ and $1.2 \mathrm{mg} / \mathrm{mL})$ are shown in Figure 5. At a concentration of $1.0 \mathrm{mg} / \mathrm{mL}$, the scavenging capacities for $S$. sinensis $\mathrm{E}+\mathrm{U}$ extract and Vitamin C were $41.2 \%$ and $92.6 \%$, respectively. Thermodynamically, the sample that has a redox potential lower than that of $\mathrm{ABTS}^{+}$may react with the radical. Although superoxide anion is a weak oxidant, it gives rise to a generation of powerful and dangerous hydroxyl radicals, as well as singlet oxygen, both of which contribute to oxidative stress [25]. The results of Sakthidevi and Mohan [26] clearly indicated that Dioscorea alata leaf extracts have a noticeable effect as a scavenging superoxide radical because of their higher total phenolic and flavonoid contents. 


\subsection{Inhibitory Effect of S. sinensis E+U Extract on Mushroom Tyrosinase Activity}

Tyrosinase plays an essential role in the melanin synthesis pathway, as it can convert L-tyrosine to L-DOPA and oxidize L-DOPA to form dopachrome. Mushroom tyrosinase is widely used as the target enzyme in screening potential inhibitors of melanogenesis. In order to analyze the $S$. sinensis $\mathrm{E}+\mathrm{U}$ extract on mushroom tyrosinase activity, tyrosinase enzyme inhibition experiments were carried out in triplicate. The inhibitory effect of $S$. sinensis $\mathrm{E}+\mathrm{U}$ extract on mushroom tyrosinase activity is shown in Figure 6 . The results show that the extract reduced mushroom tyrosinase activity in a dose-dependent manner, although it had a slightly lower inhibitory effect on mushroom tyrosinase activity than kojic acid dose did. At a concentration of $1.0 \mathrm{mg} / \mathrm{mL}$, the $S$. sinensis $\mathrm{E}+\mathrm{U}$ extract inhibitory tyrosinase activity was 33.5\%. Demirkiran et al. isolated 12 flavonoid compounds from Trifolium nigrescens Subsp. Petrisavi were evaluated for their antioxidant activity and inhibitory activity on mushroom tyrosinase [8]. Flavonoids, which are one of the most investigated groups of plant secondary metabolites, show tyrosinase inhibition [27]. Hence, S. sinensis E+U extract might act as a tyrosinase inhibitor. We also determined the effect of $S$. sinensis $\mathrm{E}+\mathrm{U}$ extract on intracellular tyrosinase activity and melanin content in B16F10 cells. S. sinensis E+U extract significantly reduced the tyrosinase activity of $\alpha-\mathrm{MSH}$-stimulated $\mathrm{B} 16 \mathrm{~F} 10$ cells $15.87 \%$ at $60 \mu \mathrm{g} / \mathrm{mL}$, the melanin production was suppressed $23.27 \%$ at $60 \mu \mathrm{g} / \mathrm{mL}$ (data not shown). In addition, the E+U extract of $S$. sinensis neither inhibited mushroom tyrosinase nor suppressed intracellular tyrosinse activity in B16F10 cells.

Figure 6. Inhibitory effect of $S$. sinensis $\mathrm{E}+\mathrm{U}$ extract on mushroom tyrosinase activity. Different concentrations of the extract or kojic acid $(0.05,0.1,0.2,0.4,0.8$ and $1.0 \mathrm{mg} / \mathrm{mL})$ were incubated with the same units of mushroom tyrosinase. Results are presented as mean $\pm \mathrm{SD}$ for the three separate experiments.

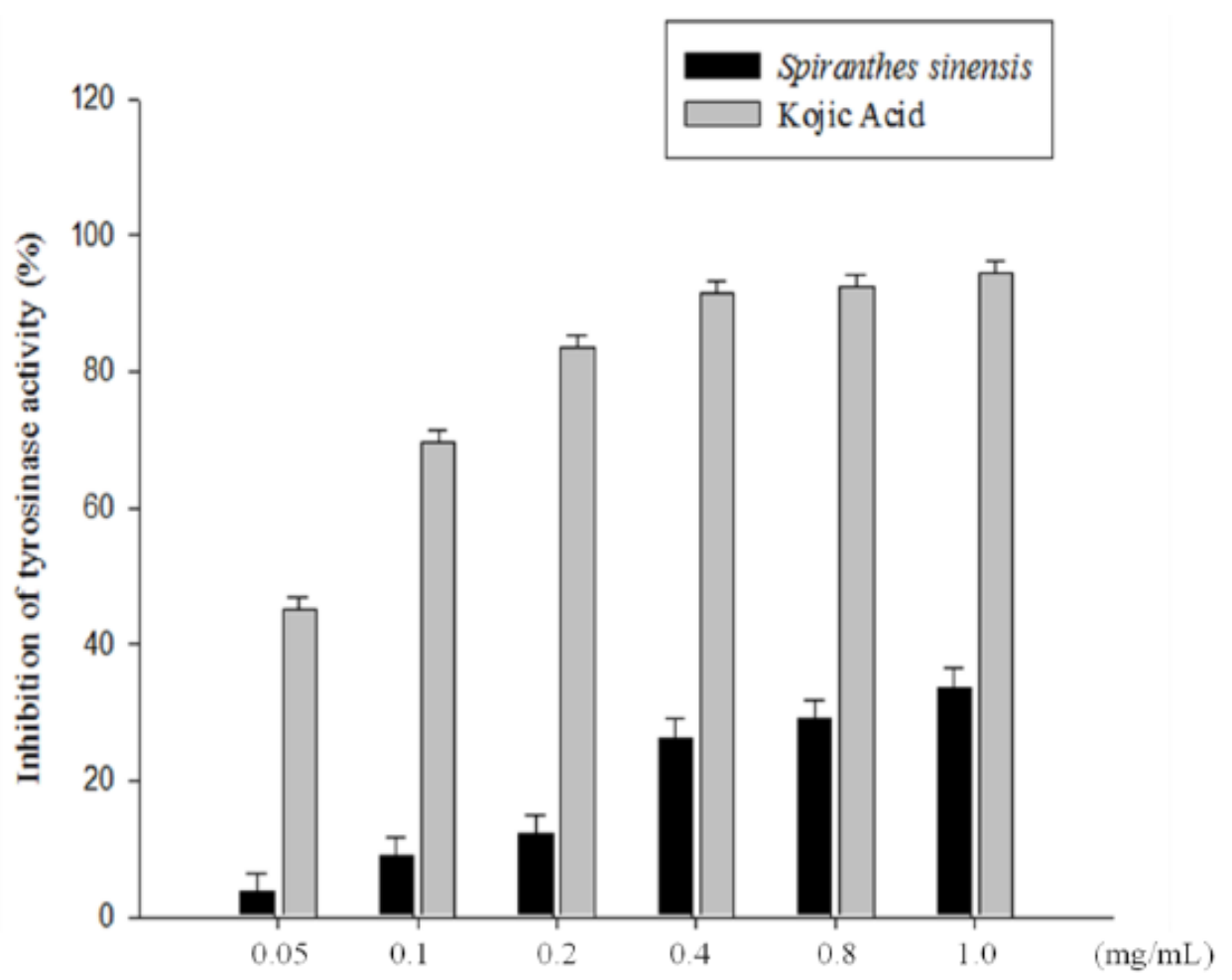




\section{Experimental}

\subsection{Plant Material}

Whole plants of $S$. sinensis were purchased in April 2010 from a local herbal medicine store in Changhua City, Taiwan. After collection, the S. sinensis samples were stored at $-20{ }^{\circ} \mathrm{C}$. Before the extraction procedures, all frozen samples were freeze-dried, then crushed by the homogenizer, sieved through a 60 -mesh screen and, finally, kept in the desiccator in properly sealed containers.

\subsection{Chemicals}

Aluminum chloride hexahydrate $\left(\mathrm{AlCl}_{3}\right)$, potassium acetate $\left(\mathrm{CH}_{3} \mathrm{COOK}\right)$, quercetin, ferulic acid, 1,1'-diphenyl-2-2'-picrylhydrazyl (DPPH), ethylenediaminetetraacetic acid (EDTA), 2,2'-azino-bis(3ethylbenzothiazoline-6-sulphonic acid (ABTS), 6-hydroxy-2,5,7,8-tetramethylchromane-2-carboxylic acid (Trolox), ferrozine, L-ascorbic acid (vitamin C), mushroom tyrosinase, L-3,4-dihydroxyphenylalanine (L-DOPA) and kojic acid were purchased from the Sigma Chemical Co. (St. Louis, MO, USA). All other chemicals used were of analytical grade.

\subsection{Extraction Procedures}

Five types of extraction methods were used in this study: water extraction (W), water extraction using UAE (W+U), 75\% ethanol extraction (E), 75\% ethanol extraction using UAE (E+U) and supercritical $\mathrm{CO}_{2}$ extraction (SFE):

Method $1(\mathrm{~W})$. Ten $\mathrm{g}$ of $S$. sinensis powder were added to $400 \mathrm{~mL}$ of water and then extracted at $60{ }^{\circ} \mathrm{C}$ for $30 \mathrm{~min}$.

Method 2 (E). Ten of $S$. sinensis powder were added to $400 \mathrm{~mL}$ of $75 \%$ ethanol and then extracted at $60{ }^{\circ} \mathrm{C}$ for $30 \mathrm{~min}$.

Method $3(\mathrm{~W}+\mathrm{U})$. Ten $\mathrm{g}$ of $S$. sinensis powder were added to $400 \mathrm{~mL}$ of water, and then extracted with an ultrasonic frequency of $40 \mathrm{kHz}$ at $60{ }^{\circ} \mathrm{C}$ for $30 \mathrm{~min}$.

Method $4(\mathrm{E}+\mathrm{U})$. Ten $\mathrm{g}$ of $S$. sinensis powder were added to $400 \mathrm{~mL}$ of $75 \%$ ethanol, and then extracted with an ultrasonic frequency of $40 \mathrm{kHz}$ at $60{ }^{\circ} \mathrm{C}$ for $30 \mathrm{~min}$.

Method 5 (SFE). Ten $\mathrm{g}$ of $S$. sinensis powders and $400 \mathrm{~mL}$ of $75 \%$ ethanol were mixed; the mixture was then placed in the extraction tank for $30 \mathrm{~min}$ at $45{ }^{\circ} \mathrm{C}$ under $18 \mathrm{MPa}$ to complete the extraction. The dynamic extraction mode was applied, and the flow rate of $\mathrm{CO}_{2}$ was $0.2 \mathrm{~L} / \mathrm{min}$. SFE was performed using a TS09-110 apparatus (Taiwan Supercritical Technology Co., Ltd., Changhua, Taiwan) by a procedure modified from the study of Chiu et al. [28].

After the $S$. sinensis extraction processes, all of the extracts were filtered by a $0.45 \mu \mathrm{m}$ filter and kept at $-20{ }^{\circ} \mathrm{C}$ for $24 \mathrm{~h}$, after which the extracts were freeze-dried and store at $4{ }^{\circ} \mathrm{C}$ for experimental use. 


\subsection{Determination of Total Flavonoid Compounds}

The total flavonoid content was determined according to the aluminum chloride colorimetric E+U described by Chang et al. [29]. Briefly, aliquots of $S$. sinensis extract $(0.1 \mathrm{~g})$ were dissolved in deionized water $(1 \mathrm{~mL})$. A portion of this solution $(0.5 \mathrm{~mL})$ was mixed with $95 \%$ ethanol $(1.5 \mathrm{~mL})$, $10 \% \mathrm{AlCl}_{3}(0.1 \mathrm{~mL}), 1 \mathrm{M} \mathrm{CH} \mathrm{COOK}_{3}(0.1 \mathrm{~mL})$ and deionized water $(2.8 \mathrm{~mL})$. After incubation at room temperature for $40 \mathrm{~min}$, the reaction mixture absorbance was measured at $415 \mathrm{~nm}$ against a de-ionized water blank on a spectrophotometer (Metertech SP8001, Taipei, Taiwan). Quercetin was chosen as a standard. Using a seven-point standard curve $(0-50 \mathrm{mg} / \mathrm{L})$, the levels of total flavonoid content in the $S$. sinensis extracts were determined in triplicate.

\subsection{Determination of Ferulic Acid}

The FA content of the five extracts was determined as per the Yang et al. method [30], with modifications. In brief, ferulic acid dissolved in 70\% ethanol was the standard (5.0, 10.0, 15.0, 20.0, $25.0 \mu \mathrm{g} / \mathrm{mL}$ ). Absorbance was then measured at $320 \mathrm{~nm}$ by a spectrophotometer. Then, the five S. sinensis extracts $(1 \mathrm{mg})$ were dissolved with $70 \%$ ethanol $(10 \mathrm{~mL})$ and measured at $320 \mathrm{~nm}$.

\subsection{In Vitro Evaluation of Antioxidant Activities}

\subsubsection{DPPH Radical Scavenging Capacity}

The DPPH radical scavenging activities of $S$. sinensis $\mathrm{E}+\mathrm{U}$ extract were determined by the method of Shimada [31], with minor modifications. Different concentrations of $S$. sinensis E+U extract were mixed with $0.1 \mathrm{mM}$ DPPH dissolved in methanol $(5 \mathrm{~mL})$. An ethanol solution of the samples $(1 \mathrm{~mL})$ with various concentrations $(0.05,0.1,0.2,0.4,0.8,1.0$ and $1.2 \mathrm{mg} / \mathrm{mL})$ was mixed with $0.1 \mathrm{mM}$ DPPH dissolved in methanol $(5 \mathrm{~mL})$. The mixture was incubated at room temperature in the dark for 20 min. The control contained all the reagents without the sample and was used as a blank. The DPPH radical scavenging capacity was determined by measuring the absorbance at $517 \mathrm{~nm}$ using a spectrophotometer. The DPPH radical scavenging capacity of vitamin $\mathrm{C}$ was also determined for comparison. The DPPH radical scavenging capacity was calculated as $(1-$ absorbance of sample/absorbance of control) $\times 100 \%$.

\subsubsection{Metal Chelating Activity}

The metal chelating activities of $S$. sinensis E+U extract were determined by the method of Decker [32], with minor modifications. An ethanol solution of the samples $(1 \mathrm{~mL})$ at various concentrations $(0.05,0.1,0.2,0.4,0.8,1.0$ and $1.2 \mathrm{mg} / \mathrm{mL})$ was mixed with methanol $(3.7 \mathrm{~mL}), \mathrm{FeCl}_{2} \cdot 4 \mathrm{H}_{2} \mathrm{O}$ $(2 \mathrm{mM}, 0.1 \mathrm{~mL})$ and ferrozine $(5 \mathrm{mM}, 0.2 \mathrm{~mL})$. The mixture stood in the dark for $10 \mathrm{~min}$. The control contained all the reagents without the sample and was used as a blank. The metal chelating activity was determined by measuring the absorbance at $562 \mathrm{~nm}$ using a spectrophotometer. The metal chelating activity of EDTA was also determined for comparison. The metal chelating activity was calculated as ( 1 - absorbance of sample/absorbance of control $) \times 100 \%$. 


\subsubsection{Total Antioxidant Activity}

The total antioxidant activities of all the samples of $S$. sinensis $\mathrm{E}+\mathrm{U}$ extract were determined by the method of Re et al. [33], with minor modifications. An ABTS radical cation $\left(\mathrm{ABTS}^{+}\right)$solution was prepared through the reaction of ABTS $(7 \mathrm{mM})$ with potassium phosphate $(2.45 \mathrm{mM})$, following incubation at room temperature in the dark for $12 \mathrm{~h}$. The $\mathrm{ABTS}^{+}$solution was then diluted with $95 \%$ ethanol to obtain an absorbance of $0.70 \pm 0.02$ at $734 \mathrm{~nm}$. Each sample $(2 \mathrm{~mL})$ or Trolox standard $(2 \mathrm{~mL})$ was added to $\mathrm{ABTS}^{+}$solution $(2 \mathrm{~mL})$ and mixed vigorously. The reaction mixture was allowed to stand at room temperature for $6 \mathrm{~min}$, and the total antioxidant activity was determined by measuring the absorbance at $734 \mathrm{~nm}$ using a spectrophotometer. The control contained all the reagents without the sample and was used as a blank. The total antioxidant activity of vitamin $C$ was also determined for comparison. The total antioxidant activity was calculated as $(1-$ absorbance of sample/absorbance of control) $\times 100 \%$.

\subsubsection{Assay of Superoxide Radical Scavenging Capacity}

The superoxide radical scavenging capacity was determined according to the method of Jing and Zhao [34]. Mixture solutions contained Tris- $\mathrm{HCl}$ buffer $(50 \mathrm{mM}, \mathrm{pH} 8.2,4.5 \mathrm{~mL}), 25 \mathrm{mM}$ pyrogallol solution $(0.4 \mathrm{~mL})$ and sample $(1 \mathrm{~mL})$ incubated at $25{ }^{\circ} \mathrm{C}$ for $5 \mathrm{~min}$. Then, $8 \mathrm{mM} \mathrm{HCl}$ solution $(1 \mathrm{~mL})$ was dripped into the mixture promptly to terminate the reaction. The absorbance was measured at $420 \mathrm{~nm}$. Vitamin C was used as the positive control. The superoxide radical scavenging capacity was calculated by the following formula:

$$
\text { Scavenging capacity }(\%)=\left[1-\left(\mathrm{A}_{1}-\mathrm{A}_{2}\right) / \mathrm{A}_{0}\right] \times 100 \%
$$

where $A_{0}$ is the absorbance of the control, $A_{1}$ is the absorbance of the sample and $A_{2}$ is the absorbance of the sample only (Tris-HCl buffer instead of pyrogallol solution).

\subsection{Mushroom Tyrosinase Inhibitor Assay}

The mushroom tyrosinase activity was determined according to the method of Rahman [35]. The tyrosinase activity was determined using L-DOPA as a substrate. Briefly, 700 units $/ \mathrm{mL}$ tyrosine solution $(50 \mu \mathrm{L})$ was dissolved in $0.1 \mathrm{M}$ of phosphate buffer $(\mathrm{pH} 6.8)$, then $50 \mu \mathrm{L}$ of each of the different concentrations of the $S$. sinensis E+U extract solution was added to each well of a 96-well plate and mixed. The assay mixture was pre-incubated at room temperature for $10 \mathrm{~min} ; 2.5 \mathrm{mM}$ L-DOPA in $0.1 \mathrm{M}$ of phosphate buffer $(\mathrm{pH} 6.8,100 \mu \mathrm{L})$ was then added to each well and incubation was continued for $20 \mathrm{~min}$ at room temperature. The amount of dopachrome formed in the reaction mixture was determined against the blank (solution without enzyme) at $475 \mathrm{~nm}$ in a microplate reader (Multiskan GO, Thermo Scientific, Waltham, MA). Kojic acid was used as a standard tyrosinase inhibitor in order to confirm that the assay was working. The percentage of tyrosinase activity was calculated as follows:

$$
\text { Tyrosinase activity }(\%)=[(\mathrm{A}-\mathrm{B}) /(\mathrm{C}-\mathrm{D})] \times 100 \%
$$

where $\mathrm{A}$ is the absorbance of the reaction mixture containing the test sample and mushroom tyrosinase, B is the absorbance of the blank sample containing the test sample but without mushroom 
tyrosinase, $\mathrm{C}$ is the absorbance of the reaction mixture without the test sample and with mushroom tyrosinase and D is the absorbance of the well without either the test sample or mushroom tyrosinase (L-DOPA alone).

\subsection{Statistical Analysis}

Results are expressed as mean \pm SD. Differences among the groups were subjected to a one-way ANOVA (analysis of variance) followed by Duncan's multiple range. Statistical significance was accepted when a $p$-value was less than 0.05 .

\section{Conclusions}

The total flavonoid compound and FA contents of extracts from $S$. sinensis prepared by five methods were investigated in the present study. E+U was determined to be a better extraction technique for obtaining higher amounts of flavonoid compounds and FA contents than the other four methods. Furthermore, flavonoid compounds and FA from $S$. sinensis showed excellent antioxidant activity in multiple test systems and was a good inhibitor of tyrosinase activity. Based on the results obtained in this study, flavonoid compounds and FA from $S$. sinensis could be beneficial to the antioxidant protection system and inhibit tyrosinase activity in health foods and cosmetic products, which would protect the human body against oxidative damage, both internally and externally.

\section{Acknowledgments}

The authors are grateful to Cheng Ching General Hospital and Horien International Co., Ltd. for its financial support of the present study.

\section{Conflicts of Interest}

The authors declare no conflict of interest.

\section{References}

1. Esther, N.M.; van Johannes, S. Antibacterial and anti-inflammatory activities of some plants used for medicinal purpose in Kenya. J. Ethnopharmacol. 2003, 87, 35-41.

2. Peng, J.Y.; Xu, Q.W.; Xu, Y.W.; Qi, Y.; Han, X.; Xu, L.N. A new anticancer dihydroflavanoid from the root of Spiranthes australis (R. Brown) Lindl. Nat. Prod. Res. 2007, 21, 641-645.

3. Lin, Y.L.; Wang, W.Y.; Kuo, Y.H.; Liu, Y.H. Homocyclotirucallane and Two Dihydrophenanthrenes from Spiranthes sinensis. Chem. Pharm. Bull. 2001, 49, 1098-1101.

4. Yasuhiro, T.; Midori, U.; Tohru, K. Studies on the constituents of Orchidaceous plants. VIII. Constituents of Spiranthes sinensis (PERS.) AMES var. amoena (M. BIEBERSON) HARA. (1). Isolation and structure elucidation of spiranthol-A, spiranthol-B, and spirasineol-A, new isopentenyldihydrophenanthrenes. Chem. Pharm. Bull. 1989, 37, 3195-3199.

5. Kelly, E.H.; Anthony, R.T.; Dennis, J.B. Flavonoid antioxidants: Chemistry, metabolism and structure-activity relationships. J. Nutr. Biochem. 2002, 13, 572-584. 
6. Erkan, N.; Ayranci, G.; Ayranci, E. Antioxidant activities of rosemary (Rosmarinus officinalis L.) extract, black seed (Nigella sativa L.) essential oil, carnosic acid, rosmarinic acid and sesamol. Food Chem. 2008, 110, 76-82.

7. Demirkiran, O.; Sabudak, T.; Ozturk, M.; Topcu, G. antioxidant and tyrosinase inhibitory activities of flavonoids from Trifolium nigrescens Subsp. petrisavi. J. Agric. Food Chem. 2013, $61,12598-12603$.

8. Kanski, J.; Aksenova, M.; Stoyanova, A.; Butterfield, D.A. Ferulic acid antioxidant protection against hydroxyl and peroxyl radical oxidation in synaptosomal and neuronal cell culture systems in vitro: Structure-activity studies. J. Nutr. Biochem. 2002, 13, 273-281.

9. Lee, H.S. Tyrosinase inhibitors of Pulsatilla cernua root-derived materials. J. Agric. Food Chem. 2002, 50, 1400-1403.

10. Lin, F.H.; Lin, J.Y.; Gupta, R.D.; Tournas, J.A.; Burch, J.A.; Selim, M.A.; Monteiro, N.A.; Grichnik, J.M.; Zielinski, J.; Pinnell, S.R. Ferulic acid stabilizes a solution of vitamins C and E and doubles its photoprotection of skin. J. Investig. Dermatol. 2005, 125, 826-832.

11. Li, Y.P.; George, K.S.; Gordon, M.E.; Dennis, K.T. Microwave-assistance provides very rapid and efficient extraction of grape seed polyphenols. Food Chem. 2011, 129, 570-576.

12. Wang, J.; Sun, B.G.; Cao, Y.P.; Tian, Y.; Li, X.H. Optimisation of ultrasound-assisted extraction of phenolic compounds from wheat bran. Food Chem. 2008, 106, 804-810.

13. Ueno, H.; Tanaka, M.; Machmudah, S.; Sasaki, M.; Goto, M. Supercritical Carbon Dioxide Extraction of Valuable Compounds from Citrus junos Seed. Food Bioprocess Tech. 2010, 1, 357-363.

14. Horžić, D.; Jambrak, A.R.; Belščak-Cvitanović, A.; Komes, D.; Lelas, V. Comparison of conventional and ultrasound assisted extraction techniques of yellow tea and bioactive composition of obtained extracts. Food Bioprocess Tech. 2012, 5, 2858-2870.

15. Takeuchi, T.M.; Rubano, M.L.; Meireles, M.A.A. Characterization and functional properties of macela (Achyrocline satureioides) extracts obtained by supercritical fluid extraction using mixtures of $\mathrm{CO}_{2}$ plus ethanol. Food Bioprocess Tech. 2010, 3, 804-812.

16. Wheeler, J.R.; McNally, E. Separation of palm kernel oil from palm kernel with supercritical carbon dioxide using pressure swing technique. J. Chromatogr. Sci. 1989, 27, 534-539.

17. Zhao, Y.G.; Wang, S.M.; Cui, H.H.; Luo, L.; Chen, C. Study on methods of extraction of flavonoids in Spiranthes australis Ladiestresses Root. Chin. J. Ethnomed. Ethnopharm. 2011, 14, 46-48.

18. Dong, M.L.; Chen, F.K.; Wu, L.J.; Gao, H.Y. A new flavonoid from the whole plant of Spiranthes australis (R. Brown) Lindl. J. Asian Nat. Prod. Res. 2005, 7, 71-74.

19. Lina, F.B.; José, A.T.; Solange, I.M. Selection of the solvent and extraction conditions for maximum recovery of antioxidant phenolic compounds from coffee silverskin. Food Bioprocess Tech. 2013, 1-11.

20. Bruni, R.; Guerrini, A.; Scalia, S.; Romagnoli, C.; Sacchetti, G. Rapid techniques for the extraction of vitamin E isomers from Amaranthus caudatus seeds: Ultrasonic and supercritical fluid extraction. Phytochem. Anal. 2002, 13, 257-261.

21. You, T.T.; Zhou, S.K.; Wen, J.L.; Ma, C.; Xu, F. Chemical composition, properties, and antimicrobial activity of the water-soluble pigments from Castanea mollisima shells. J. Agric. Food Chem. 2014, 62, 1936-1944. 
22. Husain, S.R.; Cillard, J.; Cillard, P. Hydroxyl radical scavenging activity of flavonoids. Phytochemistry 1987, 26, 2489-2491.

23. Roy, A.; Khanra, K.; Mishra, A.; Bhattacharyya, N. General analysis and antioxidant study of traditional fermented drink Handia, its concentrate and volatiles. Adv. Life Sci. 2012, 1, 54-57.

24. Luo, A.; He, X.; Zhou, S.; Fan, Y.; He, T.; Chun, Z. In vitro antioxidant activities of a water-soluble polysaccharide derived from Dendrobium nobile Lindl. extracts. Int. J. Biol. Macromol. 2009, 45, 359-363.

25. Naskar, S.; Islam, A.; Mozumdes, U.K.; Saha, P.; Haldar, P.K.; Gupta, M. In vitro and in vivo antioxidant potential of hydromethanolic extract of Phoenix dactylijera fruits. J. Sci. Res. 2010, 2 , 144-157.

26. Sakthidevi, G.; Mohan, V.R. Total phenolic, flavonoid contents and in vitro antioxidant activity of Dioscorea alata 1. Tuber. J. Food Drug Anal. 2013, 5, 115-119.

27. Kim, D.; Park, J.; Kim, J.; Han, C.; Yoon, J.; Kim, N.; Seo, J.; Lee, C. Flavonoids as Mushroom Tyrosinase Inhibitors: A Fluorescence Quenching Study. J. Agric. Food Chem. 2006, 54, 935-941.

28. Chiu, K.; Cheng, Y.; Chen, J.; Chang, C.; Yang, P. Supercritical fluids extraction of Ginkgo ginkgolides and flavonoids. J. Supercrit. Fluid. 2002, 24, 77-87.

29. Chang, C.C.; Yang, M.H.; Wen, H.M.; Chern, J.C. Estimation of total flavonoid content in propolis by two complementary colorimetric methods. J. Food Drug Anal. 2002, 10, 178-182.

30. Yang, X.; Yao, Y.Y.; Zhang, Z.Q. Determination of ferulic acid in wheat bran by derivatization combined with spectrophotometry. Food Sci. 2011, 32, 155-158.

31. Shimada, K.; Fujikawa, K.; Yahara, K.; Nakamura, T. Antioxidative properties of xanthone on the auto oxidation of soybean in cyclodextrin emulsion. J. Agric. Food Chem. 1992, 40, 945-948.

32. Decker, E.A.; Barbara, W. Role of ferritin as lipid oxidation catalyst in muscle food. J. Agric. Food. Chem. 1990, 38, 674-677.

33. Re, R.; Pellegrini, N.; Proteggente, A.; Pannala, A.; Yang, M.; Rice-Evans, C. Antioxidant activity applying an improved ABTS radical cation decolorization assay. Free Radical Biol. Med. 1999, 26, 1231-1237.

34. Jing, T.Y.; Zhao, X.Y. The improved pyrogallol method by using termination agent for superoxide dismutase measurement. Prog. Biochem. Biophys. 1995, 22, 84-86.

35. Rahman, A.U.; Choudhary, M.I.; Thomsen, W.J. Bioassay Techniques for Drug Development; Harwood Academic: Amsterdam, The Netherlands, 2001.

Sample Availability: Samples of the compounds from Spiranthes sinensis are available from the authors.

(C) 2014 by the authors; licensee MDPI, Basel, Switzerland. This article is an open access article distributed under the terms and conditions of the Creative Commons Attribution license (http://creativecommons.org/licenses/by/3.0/). 